\title{
Variation in ${ }^{125}$ I-Insulin Absorption and Blood Glucose Concentration
}

\author{
T. Lauritzen, O. K. Faber, and C. Binder \\ Hvidøre Hospital, Klampenborg, Denmark
}

\begin{abstract}
Summary. The absorption of monocomponent porcine ${ }^{125}$ I-insulin Monotard and Isophane was studied in six insulin dependent diabetic patients over a period of 12 days. The absorption of insulin was measured as the disappearance of radioactivity from sites of injection. The daily ${ }^{125} \mathrm{I}$-insulin doses ranged from 20 to 48 IU between patients. The insulin absorbed varied considerably within and between patients. The range of individual daily absorbed insulin varied from 19 to 104 per cent of the ${ }^{125} \mathrm{I}$-insulin dose. A significant correlation $(p<0.05)$ was found between insulin absorption and blood glucose concentration. Insulin absorption rates were relatively high before all hypoglycaemic episodes and reactive hyperglycaemia was only observed when relatively low insulin absorption rates followed the hypoglycaemic attack. The results show that lability in some insulin dependent diabetics is explained by variation in insulin absorption.
\end{abstract}

Key words: Insulin absorption, intermediate acting insulin, reactive hyperglycaemia, Somogyi effect, insulin dependent diabetes, insulin therapy, ${ }^{125} \mathrm{I}$-insulin, Monotard insulin, Isophane insulin.

A previous study has shown that the absorption of subcutaneous injected insulin varied significantly both between and within patients [1]. The correlation with changes in blood glucose concentration was only weak, when studied for a period of 96 hours. The absorption of a single dose of intermediate acting insulin may last for more than 96 hours [2]. The aim of the present study was to investigate the absorption of intermediate acting insulin and the diurnal varia- tion in blood glucose concentrations over a longer period (12 days).

\section{Material and Methods}

Six insulin dependent diabetic patients hospitalized because of need for better glycaemic control were studied. They were selected at random from patients with a daily insulin requirement of $24 \mathrm{IU}$ or more of which $80 \%$ or more was given in the morning as intermediate acting insulin. Patient No. 1 had prostatic hypertrophy, patient No. 2 had coronary atherosclerosis, and patient No. 3 had $x$-ray negative dyspepsia. Only two patients received medical therapy other than insulin. Patient No. 2 received digoxin $0.25 \mathrm{mg}$ once daily and patient No. 3 received glycopyrrolate $1 \mathrm{mg}$ four times daily. None had local lipodystrophies. The patients were given a solution of potassium iodide before and during the study to prevent accumulation of ${ }^{125} \mathrm{I}^{-}$in the thyroid gland. Clinical data are given in Table 1.

Informed consent was obtained from each patient before the study.

After initial stabilization of glycaemia, insulin dose, diet, and physical activity were kept constant. Each patient was investigated for twelve consecutive 24 -hour periods starting at $0800 \mathrm{~h}$.

On each morning ${ }^{125}$ I-insulin of intermediate type, was injected subcutaneously in the front of the thigh, using a new site every day. On alternate days ${ }^{125}$ I-insulin Monotard ${ }^{3}$ (Novo) or Isophane was used in each patient. Insulin Monotard and Isophane made from monocomponent porcine insulin were labelled prior to the pharmaceutical preparation as previously described [1]. The insulin was monoiodinated. The preparations contained $90 \%$ unlabelled Monotard or Isophane. The specific radioactivity was $1 \mu \mathrm{Ci} / 40 \mathrm{IU}$. Evening doses and insulin Actrapid in patient six were administered at different sites using unlabelled insulin. Morning insulin was given at $0800 \mathrm{~h}$, evening insulin at $1700 \mathrm{~h}$.

The disappearance of radioactivity from the injection sites was taken as a measure of the absorption of insulin. The absorption profile of each morning dose of intermediate insulin was determined by external counting above the injection site using collimated $2 \times 1$ "NaI-crystal in fixed geometry according to Binder [1]. The initial counting rate at each injection site was 2000 c. p. m. or more. Triplicate measurements, each lasting one minute, were performed at $0800 \mathrm{~h}, 0900,1100$ and $1500 \mathrm{~h}$ the first day and at 
Table 1. Clinical characteristics of the diabetic patients. Insulin doses refer to intermediate acting insulin except for A (Actrapid). Weight index (18)

\begin{tabular}{|c|c|c|c|c|c|c|c|c|c|c|}
\hline \multirow{2}{*}{$\begin{array}{l}\text { Patient } \\
\text { number }\end{array}$} & \multirow[t]{2}{*}{ Sex } & \multirow{2}{*}{$\begin{array}{l}\text { Age } \\
\text { (years) }\end{array}$} & \multirow{2}{*}{$\begin{array}{l}\text { Duration of } \\
\text { insulin treat- } \\
\text { ment (years) }\end{array}$} & \multicolumn{2}{|c|}{ Insulin dose (IU) } & \multirow{2}{*}{$\begin{array}{l}\text { Diet } \\
\text { (Kcal) }\end{array}$} & \multirow{2}{*}{$\begin{array}{l}\text { Weight index } \\
\text { (H. Natvig) }\end{array}$} & \multirow{2}{*}{$\begin{array}{l}\text { Retino- } \\
\text { pathy }\end{array}$} & \multirow{2}{*}{$\begin{array}{l}\text { Protein- } \\
\text { uria }\end{array}$} & \multirow{2}{*}{$\begin{array}{l}\text { Reduced } \\
\text { vibration } \\
\text { sense }\end{array}$} \\
\hline & & & & morning & evening & & & & & \\
\hline 1 & $\mathbf{M}$ & 66 & 0 & 24 & 0 & 1900 & 0.83 & background & 0 & + \\
\hline 2 & $\mathbf{M}$ & 61 & 15 & 28 & 6 & 2340 & 1.03 & background & + & + \\
\hline 3 & $\mathbf{M}$ & 20 & 6 & 48 & 8 & 2500 & 0.95 & 0 & 0 & 0 \\
\hline 4 & $F$ & 24 & 3 & 24 & 6 & 1700 & 1.03 & 0 & 0 & 0 \\
\hline 5 & $\mathbf{M}$ & 47 & 18 & 24 & 6 & 2470 & 1.00 & background & 0 & 0 \\
\hline 6 & M & 34 & 20 & $20+4 A$ & 0 & 1960 & 0.99 & proliferative & + & + \\
\hline
\end{tabular}

$0800 \mathrm{~h}$ and $1500 \mathrm{~h}$ the following days until less than $5 \%$ of the injected radioactivity remained at the site of injection.

The blood glucose concentration was determined by a glucose oxidase method on capillary blood drawn before meals at $0800 \mathrm{~h}$, $1115 \mathrm{~h}, 1430 \mathrm{~h}, 1715 \mathrm{~h}, 2000 \mathrm{~h}$ and at $0200 \mathrm{~h}$.

\section{Calculation of Data}

The insulin absorbed in a given period was calculated by adding the absorbed amount of insulin from all injection sites where absorption could still be measured.

As measurements of remaining radioactivity at the injection sites and blood glucose were not carried out simultaneously, the insulin absorbed in periods between two consecutive determinations of blood glucose concentration was calculated from the absorption curves.

Two correlations between blood glucose concentration and insulin absorption were calculated. The first correlation compared 24 hour values of mean blood glucose concentrations and absorbed amount of insulin. To minimize the influence of insulin injected before the study, results from the first 24 hours were excluded from these calculations. The second correlation between consecutive blood glucose concentration values and the insulin absorbed in the preceding 3 to 6 hours was evaluated by calculating an individual cross-correlation coefficient [3]. This statistical method was based on a general linear normal model [4].

The individual day to day variation in absorbed insulin was determined as the range between the 10 and 90 percentiles of the eleven calculated $24 \mathrm{~h}$ quantities of absorbed insulin. The individual $24 \mathrm{~h}$ mean blood glucose concentration corresponding to the above variation was calculated from the regression equation between $24 \mathrm{~h}$ mean blood glucose concentration and insulin absorption (Fig. 1). The numerical value of the slope of the regression line (Fig. 1) was used as an expression of the individual sensitivity to insulin (Table 3 ).

The quality of blood glucose control was expressed by the Mvalue [5] calculated for the study period.

Statistical tests employed were Kolmogorov-Smirnov twosample test [6], Krushall-Wallis test, Spearman rank correlation test and the above mentioned cross-correlation test. P-values less than 0.05 were considered significant.

\section{Results}

The residual amount of insulin Monotard and that of Isophane did not differ significantly in any of the patients at various times after injection (Table 2). In the further evaluation of the correlation between insulin absorption and blood glucose concentration, the data obtained with the two insulin preparations were therefore combined. The median time until $50 \%$ of the insulin had disappeared from the site of injection (T-50\%) was $10.8 \mathrm{~h}$ for insulin Monotard and $10.4 \mathrm{~h}$ for insulin Isophane.

The absorption course of intermediate insulin varied within and between patients (Fig. 1). The difference between patients was significant even as early as three hours after the injection of insulin.

The total amount of insulin absorbed from morning doses in a 24-hour period was significantly correlated with the mean blood glucose concentration for the same period in five of the six patients (Fig. 1). One day was excluded in patient No. 3 as he ingested an extra 320 calories pure carbohydrate because he felt hypoglycaemic.

The overall quality of metabolic control as expressed by the M-value was not related to either the day to day variation in absorbed insulin or the sensitivity to insulin. When the individual day to day variation in absorbed insulin was multiplied by the individual sensitivity to insulin the same ranking order was obtained as with the M-value (Table 3 ). This figure gives the variation in blood glucose concentration that corresponds to the day to day variation in insulin absorption.

The upper two panels in Fig. 2 demonstrate for patient No. 4 the consecutive blood glucose concentration and the insulin absorption rates. The lower two panels demonstrate, for the same patient, the blood glucose concentration and insulin absorption rates relative to the mean for that period of the day. It can be seen that when the insulin absorption rate was above the mean, then the blood glucose concentration was below the mean and vice versa. A significant cross-correlation coefficient between the consecutive blood glucose concentrations and insulin absorbed in the preceding 3 to 6 hours was found in all patients (Table 3), being 0.73 for the patient in Fig. 2. 


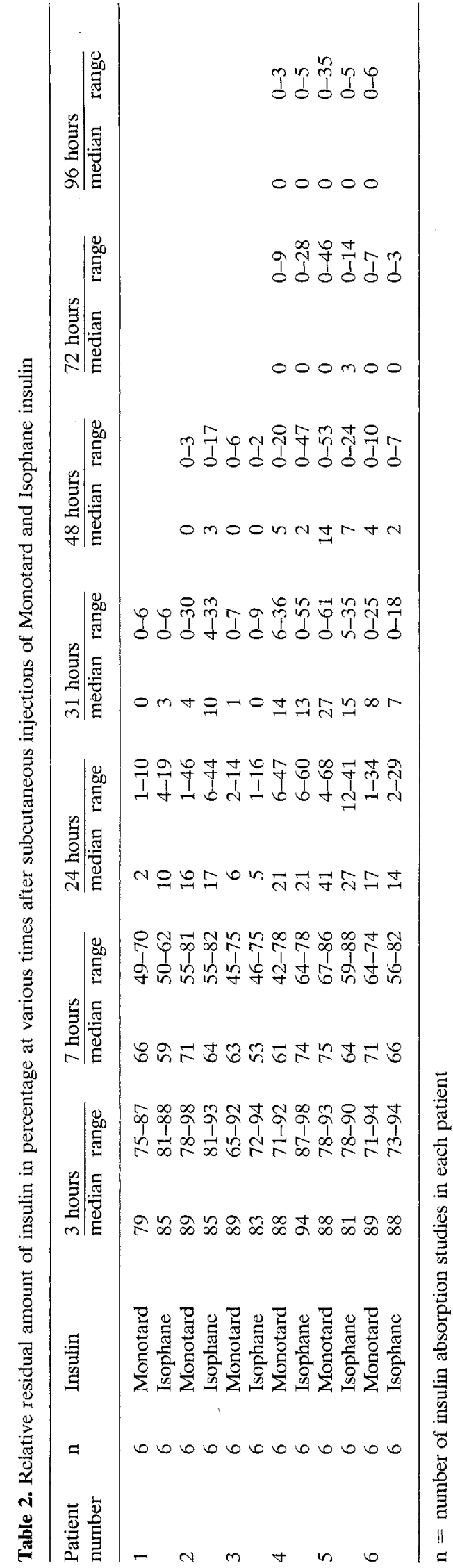

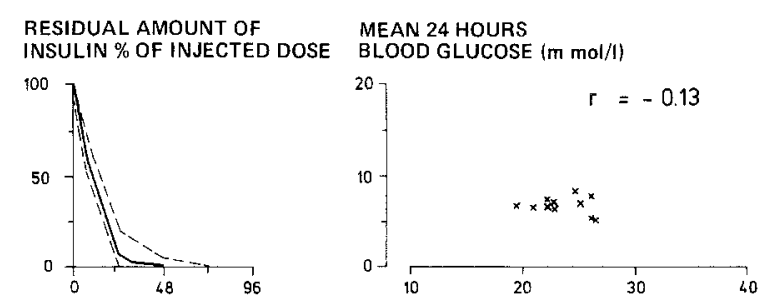
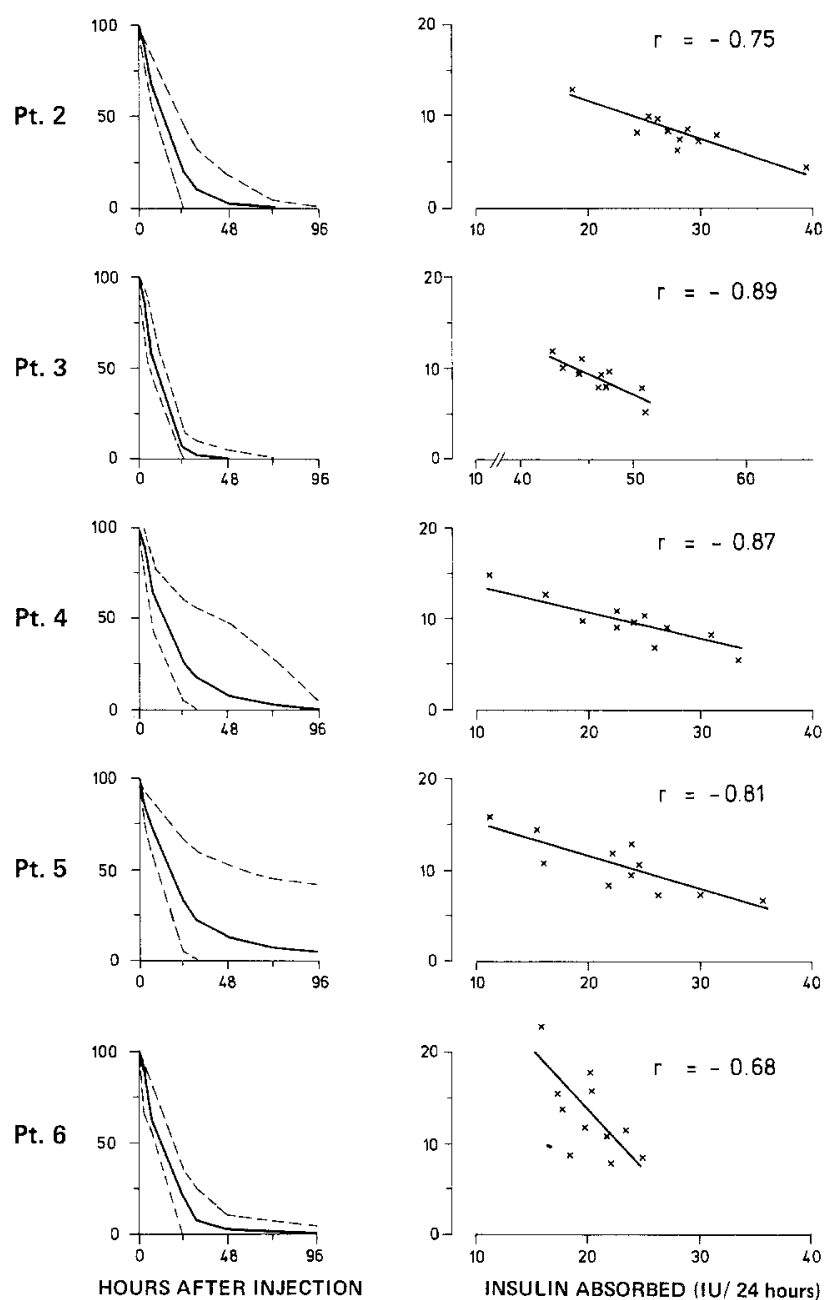

Fig. 1. Variation in insulin absorption and correlation to blood glucose concentration. Left panel: The absorption course of intermediate acting insulin in six subjects. Full line indicates the median of 12 observations, the broken lines upper and lower limits. Right panel: Correlation between the amount of insulin absorbed per 24-hour period and the mean blood glucose concentration in the same periods $(\mathrm{mmol} / \mathrm{l})$. Significant in patient Nos. 2 to $6 . \mathrm{r}=$ Spearman rank coefficient

Fourteen hypoglycaemic episodes (blood glucose concentrations $\leqslant 3 \mathrm{mmol} / \mathrm{l}$ ) were observed during the study. They were all preceded by insulin absorption rates greater than or equal to the mean insulin absorption rate. If the blood glucose concentration hereafter rose to values $\geqslant 10 \mathrm{mmol} / 1$ within the next 3-6 hours, the insulin absorption rate during this 
Table 3. Cross-correlation coefficients, M-value and blood glucose concentration corresponding to day to day variation in absorbed insulin. The cross-correlation coefficient expresses the correlation between consecutive blood glucose concentrations and the insulin absorbed in the preceding 3 to 6 hours; significant in all patients. The day to day variation in absorbed insulin is the range between the 10 and 90 percentiles of the eleven $24 \mathrm{~h}$ quantities of absorbed insulin. The sensitivity to insulin is the numerical value of the slope of the regression line between daily absorbed insulin and $24 \mathrm{~h}$ mean blood glucose concentration (Fig. 1). The M-value and the blood glucose concentration corresponding to the day to day variation in absorbed insulin give the same ranking of the patients

\begin{tabular}{|c|c|c|c|c|c|}
\hline $\begin{array}{l}\text { Patient } \\
\text { number }\end{array}$ & $\begin{array}{l}\text { Cross-correlation } \\
\text { coefficient }\end{array}$ & $\begin{array}{l}\text { Day to day variation in } \\
\text { absorbed insulin I. U. } \\
\text { (A) }\end{array}$ & $\begin{array}{l}\text { Insulin sensitivity } \\
\text { mmol/1 } \times \text { I. U. }{ }^{-1} \\
\text { (B) }\end{array}$ & $\begin{array}{l}\text { Blood glucose concn. } \\
\text { corresponding to the } \\
\text { day to day variation } \\
\text { in absorbed insulin } \\
\text { mmol/I } \\
(\mathrm{A} \times \mathrm{B})\end{array}$ & M-value \\
\hline 1 & 0.39 & 5.3 & 0.07 & 0.37 & 13.6 \\
\hline 2 & 0.70 & 6.8 & 0.38 & 2.58 & 25.0 \\
\hline 3 & 0.46 & 7.3 & 0.56 & 4.03 & 30.0 \\
\hline 4 & 0.73 & 14.7 & 0.36 & 5.29 & 32.4 \\
\hline 5 & 0.73 & 14.4 & 0.37 & 5.33 & 45.8 \\
\hline 6 & 0.74 & 6.0 & 1.12 & 6.72 & 68.7 \\
\hline
\end{tabular}
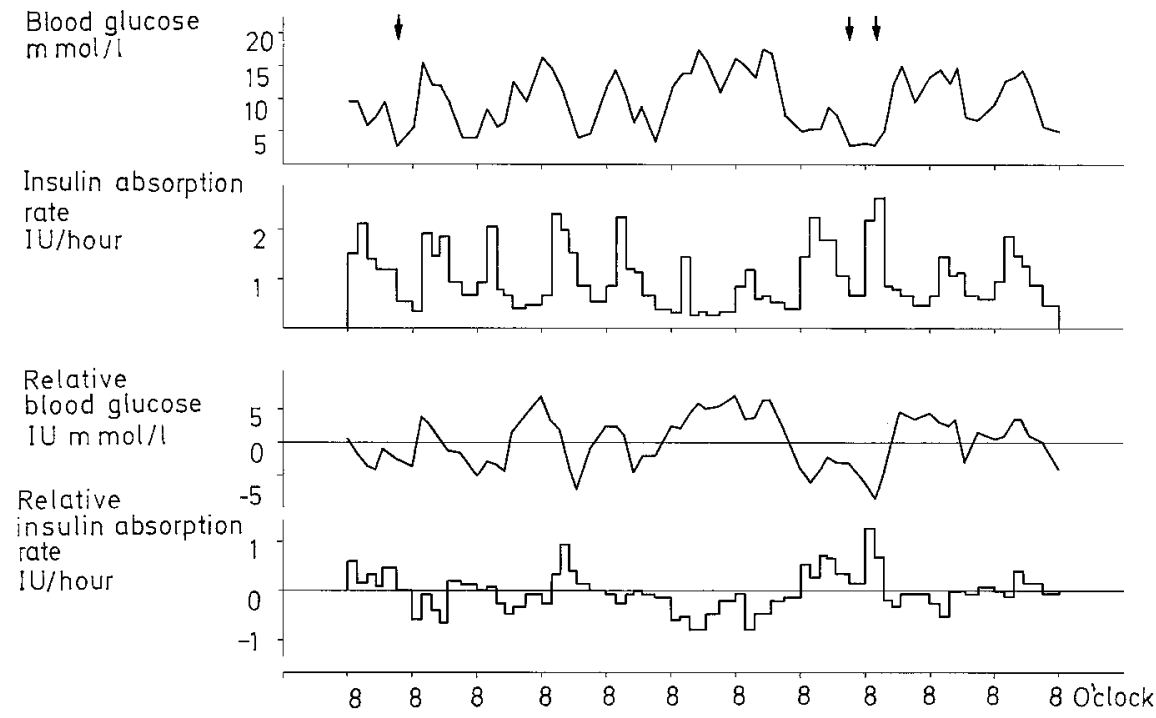

Fig. 2. Consecutive blood glucose concentrations and insulin absorption rates in patient No. 4. The upper two panels demonstrate the blood glucose concentration and absorbed amount of insulin through the eleven days of investigation for patient No. 4. The lower two panels illustrate for the same patient the blood glucose concentration and amount of insulin absorbed relative to the mean for that period of the day. Arrow indicates blood glucose concentrations equal to or less than $3 \mathrm{mmol} / \mathrm{l}$. The cross-correlation coefficient between blood glucose concentration and absorbed amount of insulin was $0.73(\mathrm{p}<0.01)$ period was less than or equal to the mean absorption rate. If the blood glucose concentration within 3-6 hours after a hypoglycaemic episode only rose to values $\leqslant 10 \mathrm{mmol} / \mathrm{l}$, the insulin absorption rates were greater than or equal to the mean absorption rate.

\section{Discussion}

Insulin dependent diabetes mellitus is characterized by a higher and more variable blood glucose concentration than that found in normal subjects [7]. Several factors such as diet, physical activity [8], mental and physical stress [9], residual secretion of insulin $[10,11,12]$ and other hormones such as glucagon $[12,13]$, glucocorticoids [14] and catecholamines
[15], together with the injected insulin determine the blood glucose concentration in insulin treated diabetics.

For practical reasons it was not possible to measure the absorption of the evening insulin doses which contributed less than $20 \%$ of the total daily insulin dose.

The results seem to indicate that intra-individual variation in insulin absorption is important for the blood glucose concentration in these patients. It is demonstrated that individual values of mean 24 hour blood glucose concentration and corresponding calculated quantity of insulin absorbed (Fig. 1) were correlated with the lowest mean 24 hour blood glucose concentration corresponding to the highest insulin absorption rate. This calculation was statistically 
significant at the $5 \%$ level in all but one patient. The latter patient [1] had only been treated with insulin for 2 weeks after several years of treatment with diet alone. It is most probable that he had a significant endogenous insulin production, which is known to contribute to the blood glucose regulation, thereby masking an effect of the day-to-day variation in insulin absorption rate [16]. Furthermore, he had the smallest variation in insulin absorption rate.

The patients could be ranked according to the overall quality of metabolic control as expressed by the $\mathrm{M}$-value. When the day-to-day variation in absorbed insulin and sensitivity to insulin were taken together the same ranking order was obtained as with the M-value.

When Somogyi tried to explain the hyperglycaemic rebound following hypoglycaemia, he presumed that the insulin absorption rate was constant [17]. In this study all events with low blood glucose concentration were preceded by a period of increased insulin absorption as compared to the average. If hyperglycaemia ensued, this was accompanied by a relative low insulin absorption. Thus fluctuations in insulin absorption may induce changes in blood glucose concentration that mimic the Somogyi effect.

The factors that determine the absorption of insulin are poorly defined. Local blood flow seems to be of importance as shown for intramuscular injections of Actrapid [1]. Preliminary studies suggest a major role of the subcutaneous blood flow for the insulin absorption after subcutaneous insulin injection (Unpublished data).

Acknowledgements. We thank Novo Research Institute for supplying us with iodinated insulin preparations and Aage Vølund for statistical help concerning the calculation of cross-correlation coefficients.

\section{References}

1. Binder, C.: Absorption of injected insulin. Copenhagen: Munksgaard 1969

2. Faber, O. K., Lauritzen, T., Binder, C., Mouridsen, H. T., Vølund, Aa.: Comparison of absorption and clinical effect of insulin Monotard ${ }^{\circledR}$ and insulin Novo Lente ${ }^{(1)}$. Ugeskr. Laeger. 43, 2510-2514 (1975)

3. Kendall, M. G., Stuart, A.: The advanced theory of statistics. Vol. III, p. 472-503. London: Charles Gritten and Company Limited 1966
4. Rao, C. R.: Linear statistical inference and its applications. 2nd Ed., p. 220-313. New York: John Wiley and Sons 1973

5. Schlichtkrull, J., Munck, O., Jersild, M.: M-value, an index of blood sugar control in diabetics. Acta Med. Scand. 177, 95-102 (1965)

6. Campbell, R. C.: Statistics for biologists. 2nd Ed., p. 71-72. Cambridge: Cambridge University Press 1974

7. Alberti, K. G. M. M., Dornhorst, A., Rowe, A. S.: Metabolic rhythms in normal and diabetic man. Isr. J. Med. Sci. 11, 571-580 (1975)

8. Lawrence, R. D.: The effect of exercise on insulin action in diabetes. Br. Med. J. 1926 I, 648-650

9. Aärimaa, M., Slätis, P., Haapaniemi, L., Jeglinsky, B.: Glucose tolerance and insulin response during and after skeletal surgery. Ann. Surg. 179, 926-929 (1974)

10. Faber, O. K., Binder, C.: B-cell function and blood glucose control in insulin dependent diabetics within the first month of insulin treatment. Diabetes 13, 263-268 (1977)

11. Faber, O. K., Binder, C.: Plasma C-peptide during the first years of insulin dependent diabetes mellitus. In: Diabetes. Proceedings of the IX Congress of the International Diabetes Federation, New Delhi, Oct. 31-Nov. 5, 1976. Bajaj, J.S. (Ed.), pp. 149-154. Amsterdam: Excerpta Medica 1977

12. Shima, K., Tanaka, R., Monishita, S., Tarui, S., Kumahara, Y., Nishikawa, M.: Studies on the etiology of "Brittle Diabetes". Diabetes 26, 717-725 (1977)

13. Reynolds, C., Molnar, G. D., Horwitz, D. L., Rubenstein, A. H., Taylor, W. F., Jiang, N.-S.: Abnormalities of endogenous glucagon and insulin in unstable diabetes. Diabetes $\mathbf{2 6}$, 36-45 (1977)

14. Olefsky, J. M., Kimmerling, G.: Effects of glucocorticoids on carbohydrate metabolism. Am. J. Med. Sci. 271, 202-210 (1976)

15. Spergel, G., Bleicher, S. J., Erbel, N. H.: Carbohydrate and fat metabolism in patients with pheochromocytoma. N. Engl. J. Med. 278, 803-807 (1968)

16. Madsbad, S., Faber, O. K., Binder, C., McNair, P., Christiansen, C., Transbøl, I.: Prevalence of residual betacell function in insulin-dependent diabetics in relation to age at onset and duration of diabetes. Diabetes 27 (Suppl. 1), 207--209 (1978)

17. Somogyi, M.: Exacerbation of diabetes by excess of insulin action. Am. J. Med. 26, 169-191 (1959)

18. Natvig, H.: Nye Hoeyde-vekttabeller for norske kvinner og men. Oslo: Landsforeningen for kost og helse 1956

Received: August 4, 1978,

and in revised form: May 29, 1979

Torsten Lauritzen

Medical Department C

Herlev University Hospital

Herlev Ringvej

DK-2730 Herlev

Denmark 